\title{
Serum Cytokine Levels are related to Nesfatin-1/NUCB2 Expression in the Implantation Sites of Spontaneous Abortion Model of CBA/j $\times$ DBA/2 Mice
}

\author{
Yiwa Chung, Heejeong Kim, Sojeong Seon and Hyunwon Yang \\ Department of Bioenvironmental Technology, College of Natural Sciences, \\ Seoul Women's University, Seoul 01797, Korea
}

\begin{abstract}
The process of spontaneous abortion involves a complex mechanism with various cytokines, growth factors, and hormones during the pregnancy. However, the mechanism underlying spontaneous abortion by pro- and antiinflammatory cytokines in the serum during the pregnancy is not fully understood. Therefore, the purpose of this study was to examine the relationship between the serum levels of pro- and anti-inflammatory cytokines and spontaneous abortion using the $\mathrm{CBA} / \mathrm{j} \times \mathrm{DBA} / 2$ mouse model. Serum levels of pro-inflammatory cytokines, such as IFN- $\gamma$, IL- $1 \alpha$ and TNF- $\alpha$ were not increased in abortion model mice, but anti-inflammatory cytokines, such as IL-4, IL-13 and IL-1ra were decreased compared to normal pregnant mice. In addition, serum levels of chemokine, such as SDF-1, G-CSF, M-CSF, IL-16, KC and MCP-1 were decreased in abortion model mice compared to normal pregnant mice. However, the expression levels of nesfatin-1/NUCB2 mRNA and protein in the uteri of implantation sites were significantly higher in abortion model mice than normal pregnant mice. These results suggest that uterine nesfatin-1/NUCB2 expression may be down-regulated by inflammatory cytokines and chemokines in the serum of pregnant mice. Moreover, this study suggests the possibility that nesfatin-1/NUCB2 expressed in the implantation sites may be associated with the maintenance of pregnancy.
\end{abstract}

Key words : Nesfatin-1, Cytokine, Chemokine, Nesfatin-1/NUCB2, Spontaneous abortion

\section{INTRODUCTION}

Spontaneous abortion, also known as miscarriage is the natural death of an embryo or fetus before 20 weeks of pregnancy without surgical procedure for a human (Sierra $\&$ Stephenson, 2006). Several mechanisms have previously been described for pathogenesis of spontaneous abortion, including chromosomal anomalies, hormonal problems, uterine abnormalities, infections, and autoimmune disorders (Quenby et al., 2002). The mechanisms by which the fetus is protected from the maternal immune system during pregnancy are not fully understood. Tolerance of the fetus by the maternal immune system is thought to depend on the interactions of many cytokines produced by the uterus and transferred from maternal serum to the site of implantation.

In humans, the endometrium develops into decidua to be receptive the embryos during the implantation window under the influence of gestational hormones and cytokines produced by maternal tissues. Communication between trophoblastic cells in the embryos and decidual cells in the uterus is mediated by cytokines and cell surface receptors

\footnotetext{
Manuscript received February 2, 2017, Received in revised form February 8, 2017, Accepted February 14, 2017

${ }_{\dagger}$ Corresponding Author : Hyunwon Yang, Department of Bioenvironmental Technology, Seoul Women's University, 126 Gongreung-Dong, Nowon-Gu, Seoul 01797, Korea. Tel.: +82-2-970-5662, Fax: +82-2-970-5974, Email: hwyang@swu.ac.kr

This is an Open Access article distributed under the terms of the Creative Commons Attribution Non-Commercial License (http:// creativecommons.org/licenses/by-nc/3.0) which permits unrestricted non-commercial use, distribution, and reproduction in any medium, provided the original work is properly cited.
} 
(Saini et al., 2011). Many cytokines are produced by trophoblastic and immune cells present within the decidua which include mainly $\mathrm{T}$ lymphocytes, macrophages and natural killer cells (van Mourik et al., 2009). Cytokines are commonly classified in one or the other category: interleukin-1 (IL-1), tumor necrosis factor (TNF), gamma-interferon (IFN-gamma), IL-12, IL-18 and granulocyte-macrophage colony stimulating factor (G-MCF) are well characterized as pro-inflammatory cytokines whereas IL4, IL-10, IL-13, IFN- $\alpha$ and transforming growth factor- $\beta$ are recognized as anti-inflammatory cytokines (Corripio-Miyar et al., 2007; Hanada \& Yoshimura, 2002). The net effect of an inflammatory response is determined by the balance between pro-inflammatory and anti-inflammatory cytokines. Pro-inflammatory cytokines are produced predominantly by activated macrophages and dendritic cells in the implantation sites and are involved in the up-regulation of inflammatory reactions. A high level of the pro-inflammatory $\mathrm{T}$ helper (Th)-1 and cytokines (IL-6, IL-8, and $\mathrm{TNF} \alpha$ ) characterizes early implantation (Mor \& Koga, 2008; Yoshinaga, 2008). In addition, an array of cytokines in maternal serum which are transferred to the fetus may play an important role in implantation of embryo and maintenance of pregnancy.

Nesfatin-1 protein is originally known as a regulator of appetite and energy metabolism, which is expressed in hypothalamus (Oh-I et al., 2006; Shimizu et al., 2009; Stengel et al., 2009a,b; Stengel et al., 2010; Yosten et al., 2012). Recently, nesfatin-1/NUCB2 was expressed not only in the hypothalamus, but also in the peripheral organ such as digestive organs (Stengel et al., 2009a,b; Goebel et al., 2009; Xia et al., 2012), adipose tissues (Ramanjaneya et al., 2010), cardiac organ (Mimee et al., 2012), and reproductive organs (García-Galiano et al., 2010; GarcíaGaliano et al., 2012; Gonzalez et al., 2012; Kim et al., 2011). Recently, it has been reported that nesfatin-1 expression levels are decreased significantly during pregnan- cy progresses in rat, suggesting that nesfatin-1 may play an important role during pregnancy and fetal development (Garces et al., 2014). We also previously demonstrated the expression of nesfatin-1/NUCB2 mRNA and protein in implantation sites during pregnancy (Chung et al., 2015).

However, it is not yet clear whether nesfatin-1/NUCB2 expressed in implantation site is associated with cytokines in maternal serum. Therefore, the purpose of this study was to examine the cytokine levels in maternal serum during spontaneous abortion using the $\mathrm{CBA} / \mathrm{j} \times \mathrm{DBA} / 2$ mouse model and the relationship between nesfatin-1/NUCB2 expression in implantation site and maternal serum cytokine levels.

\section{MATERIALS AND METHODS}

\section{Animal}

CBAy female mice, $\mathrm{BALB} / \mathrm{c}$ male mice, and $\mathrm{DBA} / 2$ male mice were obtained from Koatech (Korea) 7 to 8 weeks of age and the mice were kept in cages. All cages were under controlled illumination (12:12 h light/dark cycle, lights on/off: $6 \mathrm{~h} / 18 \mathrm{~h})$ and temperature $\left(22 \pm 2^{\circ} \mathrm{C}\right)$. Animals were fed a standard rodent diet and tap water ad libitum. When CBAj female mice had reached 10 weeks of age, they were mated with $\mathrm{DBA} / 2$ or $\mathrm{BALB} / \mathrm{c}$ males. $\mathrm{CBA} / \mathrm{j} \times \mathrm{DBA} / 2$ mouse combination shows pregnancy loss as a model of spontaneous abortion, whereas $\mathrm{CBA} / \mathrm{j} \times$ BALB/c combination shows normal pregnancy. The morning sighting of a vaginal plug was considered day 0.5 of pregnancy. Pregnant female mice were sacrificed on day 14.5 of pregnancy under $\mathrm{CO}_{2}$ anesthesia. Blood samples were collected from each pregnant and non-pregnant mouse as a control by cardiac puncture. Uterine tissues of the implantation sites were quickly removed, and then stored at $-70{ }^{\circ} \mathrm{C}$ for extracting total RNA preparation and protein extraction. Animal care and experimental proce- 
dures were approved by the Institutional Animal care and the use committee at the Seoul Women's University in accordance with guidelines established by the Korea Food and Drug Administration.

\section{Cytokine array}

Serum was obtained by centrifugation of blood samples at 6,000 rpm for $20 \mathrm{~min}$. Mouse Cytokine Array Panels were used according the manufacturer's instructions (ARY006, R\&D Systems, Minneapolis, MN). Briefly, each sample was diluted and mixed with a cocktail of biotinylated detection antibodies and then incubated with Mouse Cytokine Array membrane. Therefore, any cytokine/ detection antibody complex being present had been bound by its cognate immobilized capture antibody on the membrane. After washing, Streptavidin-Horseradish Peroxidase and chemiluminescent detection reagents were added sequentially. Immunoreactivity was then visualized using enhanced chemiluminescence reagent. Densitometric analysis was then performed. The intensity was measured using image J software 1.45 (NIH, Bethesda, MD, USA). The following proteins were assessed: CXCL13, C5a, G-CSF, GM-CSF, CCL1, CCL11, sICAM-1, IFN- $\gamma$, IL-1 $\alpha$, IL-1 $\beta$, IL-1ra, IL-2, IL-3, IL-4, IL-5, IL-6, IL-7, IL-10, IL-13, IL12p70, IL-16, IL-17, IL-23, IL-27, IP-10, CXCL11, KC, M-CSF, CCL2, CCL12, CXCL9, CCL3, CCL4, CXCL2, CCL5, CXCL12, CCL17, TIMP-1, TNF- $\alpha$ and TREM-1.

\section{Quantitative real-time PCR (qRT-PCR)}

Uterine tissues of the implantation sites were homogenized with RNA isoplus (TaKaRa Bio, Shiga, Japan). After chloroform extraction and isopropyl alcohol precipitation, RNA was dissolved in RNase-free DEPC (TaKaRa Bio, Shiga, Japan) solution. The RNA concentrations were measured with the Nano-drop (Thermo Fisher Scientific Inc., Waltham, MA). First strand cDNA synthesis was per- formed using the extracted RNA and oligo dT, followed by double-strand synthesis in RT buffer (Invitrogen, Carlsbad, CA) with dNTP (BIO BASIC Inc., Ontario, Canada) and RTase (Invitrogen, Carlsbad, CA). qRT-PCR was performed in buffer solution containing template cDNA, SYBR Green (Roche, Manheim, Germany), and each primer. Primer pairs were as follows: NUCB2 forward 5-AAAACCTTGGCCTGTCTGAA-3; reverse 5-CATCGATAGGAACAGCTTCCA-3 and GAPDH forward 5-TTGATGGCAACAATCTCCAC-3; reverse 5-CGTCCCGTGACAAAA-TGGT-3 (BIONICS, Korea). The optimum temperature cycling protocol was determined to be $95^{\circ} \mathrm{C}$ for $10 \mathrm{~s}$, $60{ }^{\circ} \mathrm{C}$ for $10 \mathrm{~s}$ and $72^{\circ} \mathrm{C}$ for $10 \mathrm{~s}$ using the Light Cycler 480 Real-time PCR System (Roche, Manheim, Germany).

\section{Western blot analysis}

Uterine tissues of the implantation sites were quickly removed and extracted the protein with EDTA homogenization buffer, the samples were SDS-PAGE and transferred to the PVDF membrane. The membrane was treated in a blocking solution and incubated with rabbit anti-rat nesfatin-1 antibody (H-003-22, Phoenix Pharmaceuticals) / antimouse $\beta$-actin antibody (sc-47778, Santa Cruz Biotechnology) followed by incubation with donkey anti-rabbit IgGHRP (sc-2313, Santa Cruz Biotechnology) / donkey antimouse IgG-HRP (sc-2096, Santa Cruz Biotechnology), respectively. By Using the ECL Plus Western Blotting Detection Reagents (Amersham; GE Healthcare), the membrane was detected to investigate the expression level of nesfatin-1 protein.

\section{Statistical analysis}

The results were presented as the mean and the standard error of the mean (SEM). Data were analyzed by student $t$ test. Values of $p<0.05$ were considered significant. 


\section{RESULTS}

1. The number of implantation sites in normal pregnant and abortion model mice
Implantation sites were observed and counted in normal pregnant and abortion model mice. Total number of implantation sites was significantly increased in normal pregnant $(10.15 \pm 0.58)$ compared to abortion model mice $(7.1$
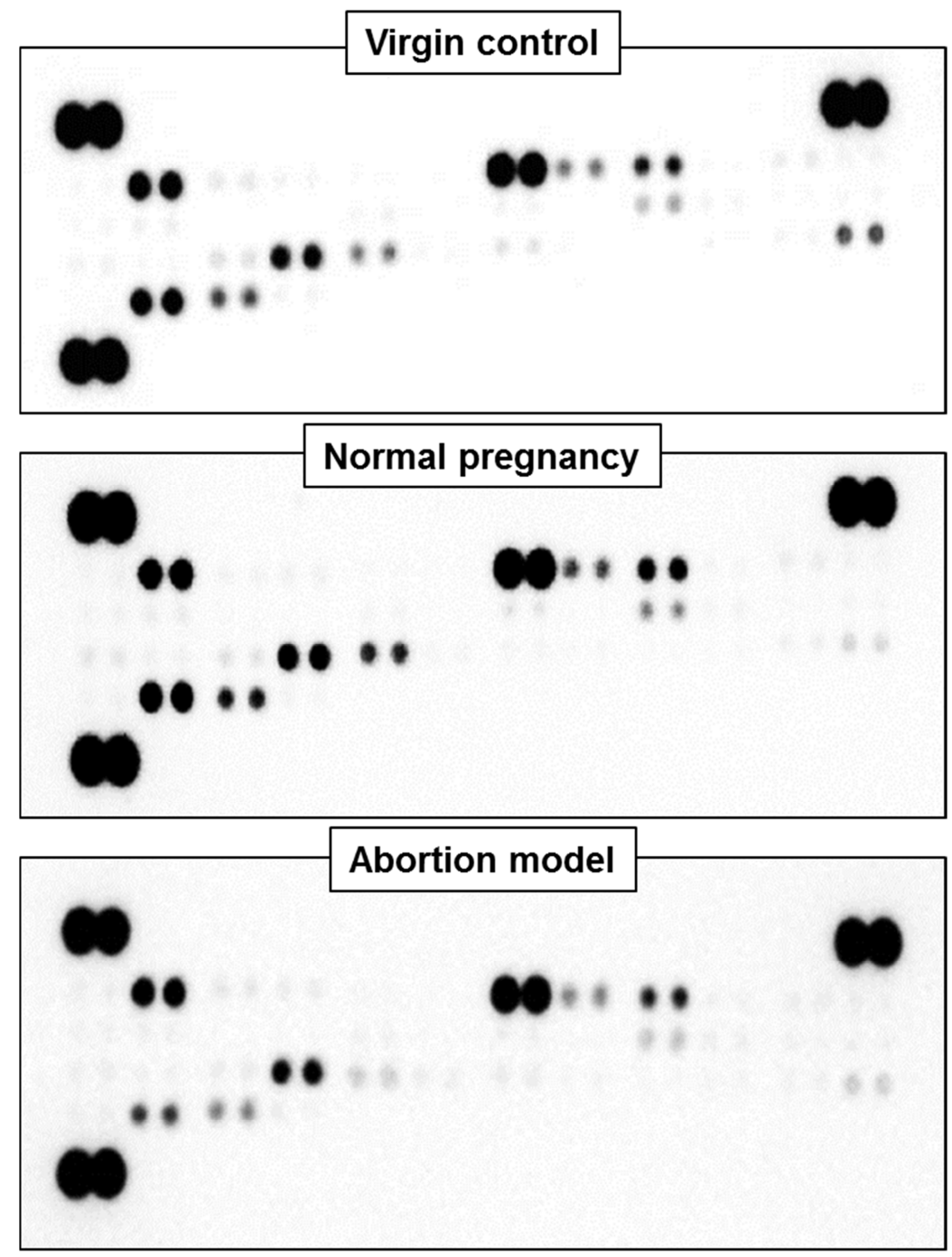

\begin{tabular}{|c|c|c|c|c|c|c|c|c|c|c|c|}
\hline $\begin{array}{l}\text { PIS } \\
\text { cont. }\end{array}$ & & & & & & & & & & & $\begin{array}{c}\text { P/S } \\
\text { cont. }\end{array}$ \\
\hline - & - & G-CSF & - & - & $\cdot$ & - & IFN-Y & IL-1a & - & IL-1ra & - \\
\hline - & IL-4 & - & - & - & - & IL-13 & - & IL-16 & - & - & - \\
\hline - & - & KC & M-CSF & MCP-1 & - & - & - & - & - & - & SDF-1 \\
\hline - & - & TNF- $\alpha$ & - & & & & & & & & \\
\hline $\begin{array}{l}\text { P/S } \\
\text { cont. }\end{array}$ & & & & & & & & & & & $\begin{array}{c}\text { N/G } \\
\text { Cont. }\end{array}$ \\
\hline
\end{tabular}

Fig. 1. Cytokine array analysis of serum on day $\mathbf{1 4 . 5}$ of pregnancy. Mouse cytokine array panel showing differences in inflammatory cytokines and chemokines in the mouse serum on day 14.5 of pregnancy. (Upper) Mouse cytokine array panel for the serum of virgin mice as non-pregnant control, (Middle) Mouse cytokine array panel for the serum of normal pregnant mice, (Lower) Mouse cytokine array panel for the serum of abortion model mice. 
$\pm 0.60)$. Interestingly, the number of implantation sites was different between the left and right uterine horn in abortion model mice, but no difference between the left and right uterine horns of normal pregnant mice (Table 1).
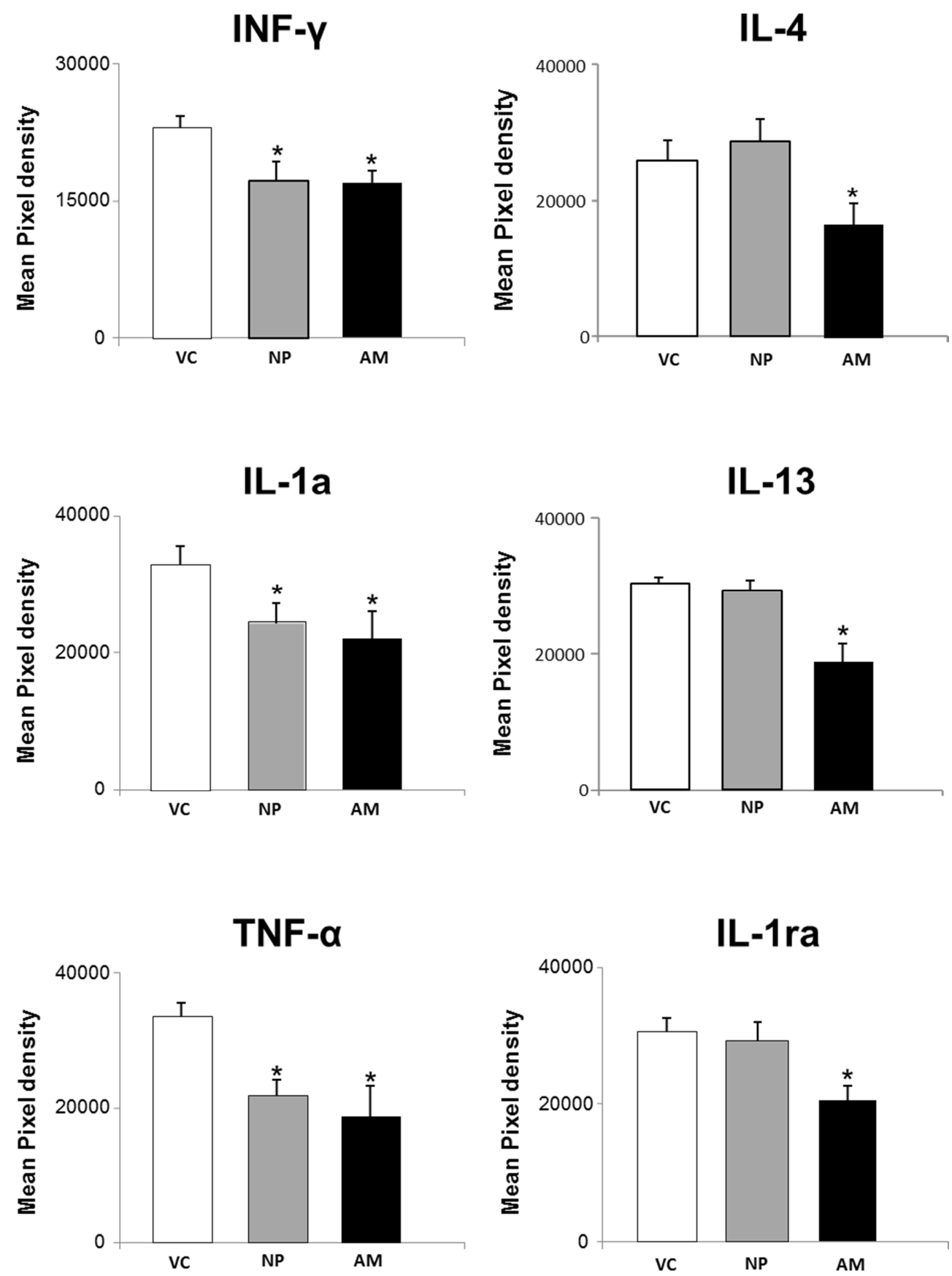

Fig. 2. Cytokine levels in serum on day 14.5 of pregnancy. Bloods of normal pregnant (NP) and abortion model mice (AM), and non-pregnant mice (VC) were collected for cytokine determination using the Mouse Cytokine Array Kit. Array images were analyzed by densitometry for mean pixel density using ImageJ software. Bars represent the mean pixel density in expression of selected cytokines and are shown as the mean \pm SEM. ${ }^{*}, p<0.05$. 
mice were analyzed using cytokine array kit. The data are expressed as relative levels of selected cytokines based on the positive controls (Fig. 1). The expression of proinflammatory cytokines, including IFN- $\gamma$, IL- $1 \alpha$ and TNF$\alpha$ was significantly decreased in both normal pregnant and abortion model mice compared to non-pregnant controls. However, their levels were not different between normal pregnant and abortion model mice. On the other hand, the expression of anti-inflammatory cytokines, including IL-4, IL-13 and IL-1ra was not decreased in normal pregnant mice compared to non-pregnant controls. However, their levels were significantly decreased in abortion model mice compared to normal pregnant (Fig. 2).

Next, we analyzed chemokines in the serum collected from normal pregnant and abortion model mice, and nonpregnant mice as a control. The expression of SDF-1 and G-CSF was significantly decreased in both normal pregnant and abortion model mice compared to non-pregnant controls, but showing no difference between normal pregnant and abortion model mice. On the other hand, the expression of M-CSF, IL-16, KC and MCP-1 was not decreased in normal pregnant mice compared to nonpregnant controls. However, their levels were significantly decreased in abortion model mice compared to normal pregnant (Fig. 3).

\section{Expression levels of nesfatin-1/NUCB2 mRNA} and protein in implantation sites of normal pregnant and abortion model mice

The expression levels of nesfatin-1/NUCB2 mRNA in the uteri of implantation sites were examined by qRT-PCR. Interestingly, the expression levels of nesfatin-1/NUCB2 mRNA was significantly higher in abortion model mice than normal pregnant mice on day 14.5 of pregnancy (Fig. $4 \mathrm{~A})$. The levels of nesfatin-1/NUCB2 protein in the uteri of implantation sites were investigated by western blotting. Nesfatin-1/NUCB2 protein levels were increased in abortion model mice compared to normal pregnant mice, simi-
Table 1. The number of implantation sites in normal pregnant and abortion model mice

\begin{tabular}{ccc}
\hline \hline & $\begin{array}{c}\text { Normal pregnant } \\
(\mathrm{n}=20)\end{array}$ & $\begin{array}{c}\text { Abortion model } \\
(\mathrm{n}=20)\end{array}$ \\
\hline Total & $10.15 \pm 0.58$ & $7.1 \pm 0.60$ \\
Left uterine & $4.8 \pm 0.28$ & $4.7 \pm 0.27$ \\
Right uterine & $5.35 \pm 0.30$ & $2.4 \pm 0.33$ \\
\hline
\end{tabular}

lar to nesfatin-1/NUCB2 mRNA expression (Fig. 4B).

\section{DISCUSSION}

Spontaneous abortion or miscarriage which is the most common complication of early pregnancy is defined as extraction of the embryo or fetus before 20-22 weeks of gestation (Baek et al., 2007). Spontaneous abortion is a multifactorial disorder resulting from genetic factors, anatomic factors, autoimmune disorders, endocrine dysfunction, thrombophilia, life style factors, and maternal infections (Wang et al., 2003; Ford \& Schust, 2009). Furthermore, spontaneous abortion process involves a complex mechanism with various cytokines, growth factors, and hormones during the pregnancy (Feldt-Rasmussen \& Mathiesen, 2011).

Nesfatin-1 is originally known for the first time to participate in the regulation of hunger as a neuropeptide produced in the hypothalamus of mammals (Oh-i et al., 2006). After that, many studies have shown that nesfatin-1/ NUCB2 is expressed not only in the hypothalamus, but also in the peripheral organs including gut, fat and heart (Mimee et al., 2012; Stengel et al., 2009a; Ramanjaneya et al., 2010). We also have reported that nesfatin-1/NUCB2 mRNA and protein is expressed in epithelial cells around the uterine glands and endometrium of mouse (Kim et al., 2014). Moreover, the nesfatin-1/NUCB2 expression was increased in the uterus of abortion model mice compared to those of normal pregnant mice (Chung et al., 2015). On the other hand, it has been reported that uterine nesfatin-1 
SDF-1

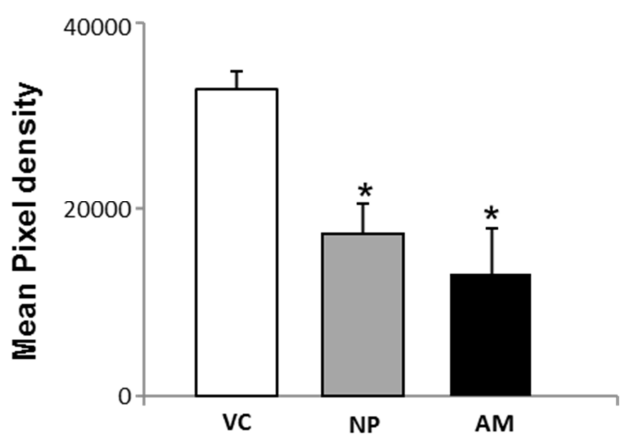

M-CSF

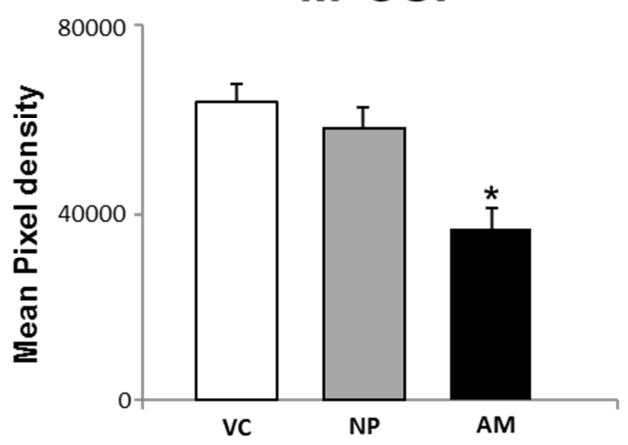

$\mathrm{KC}$

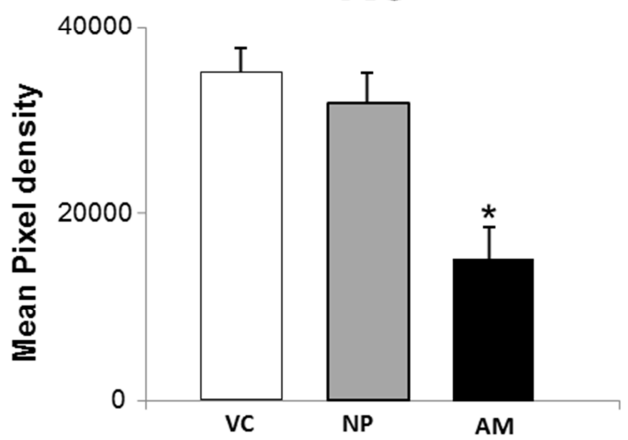

G-CSF

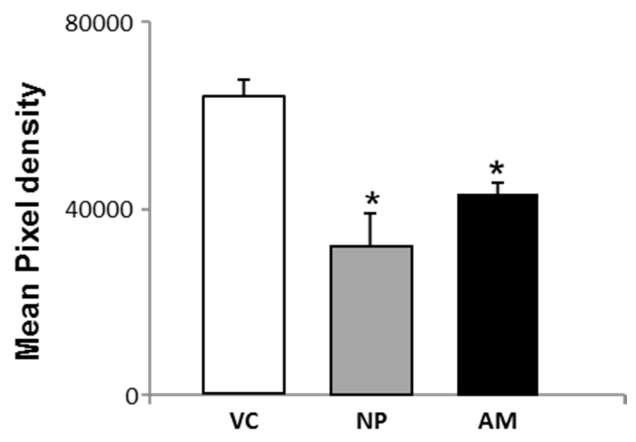

IL-16

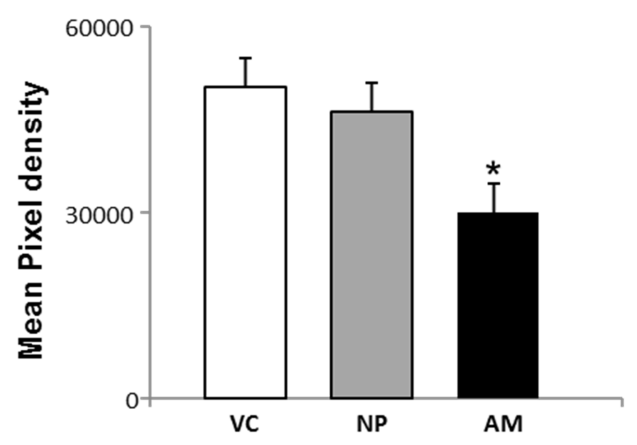

MCP-1

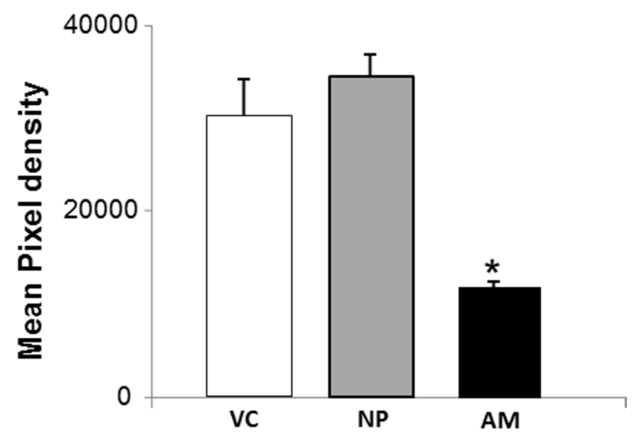

Fig. 3. Chemokine levels in serum on day 14.5 of pregnancy. Bloods of normal pregnant (NP) and abortion model mice (AM), and non-pregnant mice (VC) were collected for chemokine determination using the Mouse Cytokine Array Kit. Array images were analyzed by densitometry for mean pixel density using ImageJ software. Bars represent the mean pixel density in expression of selected chemokines and are shown as the mean \pm SEM. *, $p<0.05$

expression levels are decreased significantly during pregnancy progresses in rat (Garces et al., 2014). These results suggest that nesfatin-1 protein in the uterus may play an important role during pregnancy and fetal development. However, little is known about how nesfatin-1/NUCB2 expressed in uterus is regulated. Therefore, we hypothe- 

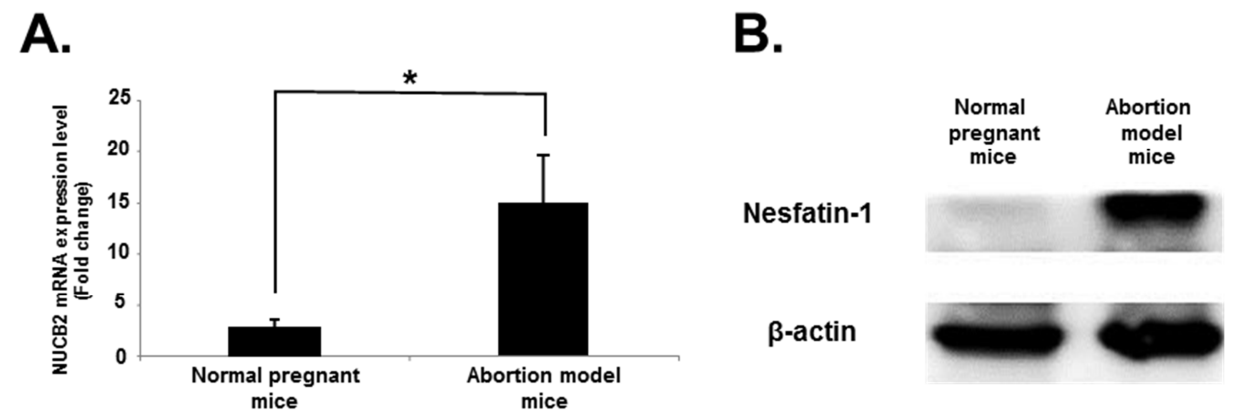

Fig. 4. Expression levels of nesfatin-1/NUCB2 mRNA and protein in the uteri of implantation sites of normal pregnant and abortion model mice. (A) The amount of NUCB2 mRNA expressed in the uteri of implantation sites was analyzed by qRT-PCR. The expression levels of NUCB2 mRNA in abortion model mice on day 14.5 of pregnancy were significantly higher than those in normal pregnant mice. All data are represented as mean $\pm \operatorname{SEM}(n=6)$. *, $p<0.05$ (B). Nesfatin-1 protein expression in the uteri of implantation sites was detected by western blotting. The expression levels of nesfatin-1 protein in the abortion site on day 14.5 of pregnancy were significantly higher those in normal pregnant mice, similar to NUCB2 mRNA expression levels.

sized that uterine nesfatin-1/NUCB2 expression could be regulated by cytokines in maternal serum during pregnancy. In this study, we examined the cytokine levels in maternal serum during pregnancy and the relationship between uterine nesfatin-1/NUCB2 expression and maternal serum cytokine levels using $\mathrm{CBA} / \mathrm{j} \times \mathrm{DBA} / 2$ combination as a spontaneous abortion model mouse and $\mathrm{CBA} / \mathrm{j} \times \mathrm{BALB} / \mathrm{c}$ combination as a normal pregnant mouse.

We first investigated the number of implantation sites to confirm the pregnancy loss in the $\mathrm{CBA} / \mathrm{j} \times \mathrm{DBA} / 2$ combination mice. Total number of implantation sites was significantly decreased in abortion model mice compared to normal pregnant. Next, we analyzed pro-and anti-inflammatory cytokine levels in the serum of normal pregnant and abortion model mice, and non-pregnant mice. IFN- $\gamma$, IL-1 and TNF are representative pro-inflammatory cytokines, and when they are administered to humans, they produce fever, inflammation, tissue destruction, and, in some cases, shock and death (Dinarello, 2000). Human pregnancy also increases the levels of IL-10, the antiinflammatory cytokine that down regulates Th1 response as well as the release of pro-inflammatory cytokines, such as IFN- $\gamma$ and TNF- $\alpha$ (Marzi et al., 1996; Jenkins et al.,
2000). IFN- $\gamma$ secreted in the uterus during early pregnancy plays critical roles that include initiation of endometrial vasculature remodeling, angiogenesis at implantation sites, and maintenance of the decidual (maternal) component of the placenta (Murphy et al., 2009). In our results, the proinflammatory cytokines, such as IFN- $\gamma$, IL- $1 \alpha$ and TNF- $\alpha$ was significantly decreased in the serum of pregnant mice, and even in abortion model mice. However, their levels were not different between normal pregnant and abortion model mice. These results suggest that down-regulation of pro-inflammatory cytokines may be critical for the process of implantation and the maintenance of pregnancy, but they may be not related to spontaneous abortion.

On the other hand, our results showed that expression of anti-inflammatory cytokines, including IL-4, IL-13 and IL$1 \mathrm{ra}$ tended to be increased in normal pregnant mice, but their levels were significantly decreased in abortion model mice. The anti-inflammatory cytokines are a series of immunoregulatory molecules that control the pro-inflammatory cytokine response (Opal \& DePalo., 2000). The production of pro-inflammatory cytokines coupled with a decrease or lack of increase in anti-inflammatory cytokines, such IL-4 and IL10 can lead to a spectrum of pregnancy 
disorders (Chatterjee et al., 2014). IL-13, predominantly secreted by activated Th2 cells, is also considered as an anti-inflammatory 'IL-4-like' molecule (Chomarat et al., 1998). Mononuclear lymphocytes, B cells, large granular lymphocytes and endothelial cells, known to be responsive to IL-13, can be traced in either the placenta or the maternal reproductive tract (McKenzie et al., 1993). IL-13 is thought to be required during the first third of gestation to support trophoblast invasion within the decidua (Zourbas et al., 2001).

In addition, we analyzed chemokines in the serum collected from normal pregnant and abortion model mice. Chemokines are a family of small cytokines having a role in leukocyte trafficking and participating in developmental processes such as differentiation and directed migration. Similar events occur in pregnancy during development of the fetal-maternal interface, where there is extensive leukocyte trafficking and tissue morphogenesis, and this is accompanied by abundant chemokine expression (Redhorse et al., 2004). We found that expression of SDF-1 and G-CSF was significantly decreased in both normal pregnant and abortion model mice, whereas M-CSF, IL-16, KC and MCP-1 were significantly decreased in abortion model mice. SDF-1/CXCR4 signaling promotes trophoblast survival during pregnancy, suggesting that alterations in SDF1 and/or CXCR4 expression or function may be associated with specific pregnancy disorders (Jaleel et al., 2004). Granulocyte colony-stimulating factor (G-CSF), a cytokine, and its receptor are expressed in placental tissue. G-CSF treatment in women with spontaneous abortion showed to increase in the delivery of a healthy baby (Scarpellini \& Sbracia, 2009). Macrophage colony stimulating factor (CSF-1 or M-CSF) is involved in haemopoiesis and probably in mouse gestation, showing that M-CSF increase early (4-8 weeks) and progressively during gestation. Sexual steroids induce its production by uterine glandular epithelial cells and its receptor is expressed on placental trophoblastic cells. This locally produced M-CSF could play a role in human pregnancy (Praloran et al., 1994). MCP-1 was higher in pregnant women (women with gestational diabetes mellitus and without) than in nonpregnant women. MCP-1 was elevated in patients with gestational diabetes mellitus (GDM) in the third trimester compared to healthy pregnant women, suggesting an association between inflammation and GDM (Klein et al., 2008).

In the present study, we also showed that nesfatin1/NUCB2 mRNA and protein were expressed in uteri of implantation sites of normal pregnant and abortion model mice during the pregnancy. Interestingly, the expression levels of nesfatin-1/NUCB2 mRNA and protein were significantly higher in abortion model mice than normal pregnant mice. Given the cytokine array results, nesfatin1/NUCB2 expression in the uterus of implantation site may be regulated cytokines and chemokines in the serum.

The present study demonstrated that serum levels of pro-inflammatory cytokines were not increased in abortion model mice, but anti-inflammatory cytokines were decreased compared to normal pregnant mice. In addition, serum chemokine levels also were decreased in abortion model mice compared to normal pregnant mice. By contrast, the expression levels of nesfatin-1/NUCB2 mRNA and protein in the uteri of implantation sites were significantly higher in abortion model mice than normal pregnant mice. These results suggest that uterine nesfatin-1/NUCB2 expression may be down-regulated by inflammatory cykokines (IL-4, IL-13, IL-1ra, IFN- $\gamma$, IL-1 $\alpha$ and TNF- $\alpha$ ) and chemokines (SDF-1, G-CSF, M-CSF, IL-16, KC and MCP-1) in the serum of pregnant mice. Moreover, this study suggests the possibility that nesfatin-1/NUCB2 expressed in the implantation sites may be associated with the maintenance of pregnancy.

\section{ACKNOWLEDGEMENT}

This study was supported by a grant of the Korean Health Technology R\&D Project through the Korea Health 
Industry Development Institute(KHIDI), funded by the Ministry of Health \& Welfare, Republic of Korea. (Grant Number: A120136). This work was supported by a research grant from Seoul Women’s University (2017).

\section{REFERENCES}

Baek KH, Lee EJ, Kim YS (2007) Recurrent pregnancy loss: the key potential mechanisms. Trends Mol Med 13:310-317.

Chatterjee P, Chiasson VL, Bounds KR, Mitchell BM (2014) Regulation of the anti-inflammatory cytokines interleukin-4 and interleukin-10 during pregnancy. Front Immunol 5:253.

Chomarat P, Banchereau J (1998) Interleukin-4 and interleukin-13: their similarities and discrepancies. Int Rev Immunol 94:1-52.

Chung Y, Kim H, Im E, Kim P, Yang H (2015) Th 17 cells and nesfatin-1 are associated with spontaneous abortion in the $\mathrm{CBA} / \mathrm{j} \times \mathrm{DBA} / 2$ mouse model. Dev Reprod 19:243-252.

Corripio-Miyar Y, Bird S, Tsamopoulos K, Secombes CJ (2007) Cloning and expression analysis of two proinflammatory cytokines, IL-1 beta and IL- 8 , in haddock (Melanogrammus aeglefinus). Mol Immunol 44: 1361-1373.

Dinarello CA (2000) Proinflammatory cytokines. Chest 118:503-508.

Feldt-Rasmussen U, Mathiesen ER (2011) Endocrine disorders in pregnancy: physiological and hormonal aspects of pregnancy. Best Pract Res Clin Endocrinol Metab 25:875-884.

Ford HB, Schust DJ (2009) Recurrent pregnancy loss: etiology, diagnosis, and therapy. Rev Obstet Gynecol 2:76-83.

Garces MF, Poveda NE, Sanchez E, Sanchez AY, Bravo SB, Vazquez MJ, Dieguez C, Nogueiras R, Caminos JE (2014) Regulation of NucB2/Nesfatin-1 throughout rat pregnancy. Physiol Behav 133:216-222.

García-Galiano D, Navarro VM, Gaytan F, Tena-Sempere M (2010) Expanding roles of NUCB2/nesfatin-1 in neuroendocrine regulation. J Mol Endocrinol 45:281290.

García-Galiano D, Pineda R, Ilhan T, Castellano JM, RuizPino F, Sánchez-Garrido MA, Vazquez MJ, SangiaoAlvarellos S, Romero-Ruiz A, Pinilla L, Diéguez C, Gaytán F, Tena-Sempere M (2012) Cellular distribution, regulated expression, and functional role of the anorexigenic peptide, NUCB2/nesfatin-1, in the testis. Endocrinology 153:1959-1971.

Goebel M, Stengel A, Wang L, Lambrecht NW, Taché Y (2009) Nesfatin-1 immunoreactivity in rat brain and spinal cord autonomic nuclei. Neurosci Lett 452:241246.

Gonzalez R, Shepperd E, Thiruppugazh V, Lohan S, Grey C, Chang JP, Unniappan S (2012) Nesfatin-1 regulates the hypothalamo-pituitary-ovarian axis of fish. Biol Reprod 87:1-11.

Hanada T, Yoshimura A (2002) Regulation of cytokine signaling and inflammation. Cytokine Growth Factor Rev 13:413-421.

Jaleel MA, Tsai AC, Sarkar S, Freedman PV, Rubin LP (2004) Stromal cell-derived factor-1 (SDF-1) signalling regulates human placental trophoblast cell survival. Mol Hum Reprod 10:901-909.

Jenkins C, Roberts J, Wilson R, MacLean MA, Shilito J, Walker JJ (2000) Evidence of a T(H) 1 type response associated with recurrent miscarriage. Fertil Steril 73: 1206-1208.

Kim J, Chung Y, Kim H, Im E, Lee H, Yang H (2014) The tissue distribution of nesfatin-1/NUCB2 in mouse. Dev Reprod 18:301-309.

Kim J, Kim H, Kim S, Cho H, Hwang S, Moon C, Yang H (2011) Expression of nesfatin-1/NUCB2 and its binding site in mouse testis and epididymis. Dev Reprod 15:249-256. 
Klein K, Satler M, Elhenicky M, Brix J, Krzyzanowska K, Schernthaner G, Husslein PW, Schernthaner GH (2008) Circulating levels of MCP-1 are increased in women with gestational diabetes. Prenat Diagn 28:845-851.

Marzi M, Vigano A, Trabattoni D, Villa ML, Salvaggio A, Clerici E, Clerici M (1996) Characterization of type 1 and type 2 cytokine production profile in physiologic and pathologic human pregnancy. Clin Exp Immunol 106:127-133.

McKenzie AN, Li X, Largaespada DA, Sato A, Kaneda A, Zurawski SM, Doyle EL, Milatovich A, Francke U, Copeland NG, Jenkins NA, Zurawski G (1993) Structural comparison and chromosomal localization of the human and mouse IL-13 genes. J Immunol 150:54365444.

Mimee A, Smith PM, Ferguson AV (2012) Nesfatin-1 influences the excitability of neurons in the nucleus of the solitary tract and regulates cardiovascular function. Am J Physiol Regul Integr Comp Physiol 302:12971304.

Mor G, Koga K (2008) Macrophages and pregnancy. Reprod Sci 15:435-436.

Murphy SP, Tayade C, Ashkar AA, Hatta K, Zhang J, Croy BA (2009) Interferon gamma in successful pregnancies. Biol Reprod 80:848-859.

Oh-I S, Shimizu H, Satoh T, Okada S, Adachi S, Inoue K, Eguchi H, Yamamoto M, Imaki T, Hashimoto K, Tsuchiya T, Monden T, Horiguchi K, Yamada M, Mori M (2006) Identification of nesfatin-1 as a satiety molecule in the hypothalamus. Nature 443:709-712.

Opal SM, DePalo VA (2000) Anti-inflammatory cytokines. Chest 117:1162-1172.

Praloran V, Coupey L, Donnard M, Berrada L, Naud MF (1994) Elevation of serum M-CSF concentrations during pregnancy and ovarian hyperstimulation. Br J Haematol 86:675-677.

Quenby S, Vince G, Farquharson R, Aplin J (2002) Recur- rent miscarriage: a defect in nature's quality control? Hum Reprod 17:1959-1963.

Ramanjaneya M, Chen J, Brown JE, Tripathi G, Hallschmid M, Patel S, Kern W, Hillhouse EW, Lehnert H, Tan BK, Randeva HS (2010) Identification of nesfatin1 in human and murine adipose tissue: a novel depot specific adipokine with increased levels in obesity. Endocrinology 151:3169-3180.

Red-Horse K, Drake PM, Fisher SJ (2004) Human pregnancy : the role of chemokine networks at the fetalmaternal interface. Expert Rev Mol Med 6:1-14.

Saini V, Arora S, Yadav A, Bhattacharjee J (2011) Cytokines in recurrent pregnancy loss. Clin Chim Acta 412:702-708.

Scarpellini F, Sbracia F (2009) Use of colony-stimulating factor for the treatment of unexplained recurrent miscarriage: a randomised controlled trial. Hum Reprod $11: 2703-2708$.

Shimizu H, Ohsaki A, Oh-I S, Okada S, Mori M (2009) A new anorexigenic protein, nesfatin-1. Peptides 30:995998.

Sierra S, Stephenson M (2006) Genetics of recurrent pregnancy loss. Semin Reprod Med 24:17-24.

Stengel A, Goebel M, Taché Y (2010) Nesfatin-1: a novel inhibitory regulator of food intake and body weight. Obes Rev 12:261-271.

Stengel A, Goebel M, Wang L, Rivier J, Kobelt P, Mönnikes H, Lambrecht NW, Taché Y (2009a) Central nesfatin-1 reduces darkphase food intake and gastric emptying in rats: differential role of corticotropin-releasing factor 2 receptor. Endocrinology 150:4911-4919.

Stengel A, Goebel M, Wang L, Taché Y (2009b) Ghrelin, des-acyl ghrelin and nesfatin-1 in gastric X/A-like cells role as regulators of food intake and body weight. Peptides 31:357-369.

van Mourik MS, Macklon NS, Heijnen CJ (2009) Embryonic implantation: cytokines, adhesion molecules, and 
immune cells in establishing an implantation environment. J Leukocyt Biol 85:4-19.

Wang X, Chen C, Wang L, Chen D, Guang W, French J (2003) Conception, early pregnancy loss, and time to clinical pregnancy: a population-based prospective study. Fertil Steril 79:577-584.

Xia ZF, Fritze DM, Li JY, Chai B, Zhang C, Zhang W, Mulholland MW (2012) Nesfatin-1 inhibits gastric acid secretion via a central vagal mechanism in rats. Am J Physiol Gastrointest Liver Physiol 303:570-577.

Yoshinaga K (2008) Review of factors essential for blasto- cyst implantation for their modulating effects on the maternal immune system. Semin Cell Dev Biol 19: 161-169.

Yosten GL, Redlinger L, Samson WK (2012) Evidence for a role of endogenous nesfatin-1 in the control of water drinking. J Neuroendocrinol 24:1078-1084.

Zourbas S, Dubanchet S, Martal J, Chaouat G (2001) Localization of pro-inflammatory (IL-12, IL-15) and antiinflammatory (IL-11, IL-13) cytokines at the foetomaternal interface during murine pregnancy. Clin Exp Immunol 126:519-528. 